\title{
Linguistic Sexism in The Times-A Diachronic Study
}

\author{
Tarutuulia Laine $^{1} \&$ Greg Watson ${ }^{1}$ \\ ${ }^{1}$ University of Eastern Finland, Finland \\ Correspondence: Greg Watson, School of Humanities, University of Eastern Finland, Joensuu Campus, Joensuu, \\ Finland. Tel: 358-294-452-160. E-mail: greg.watson@uef.fi
}

Received: January 23, 2014 Accepted: February 25, 2014 Online Published: May 27, 2014

doi:10.5539/ijel.v4n3p1

URL: http://dx.doi.org/10.5539/ijel.v4n3p1

\begin{abstract}
This paper discusses aspects of linguistic sexism in the British newspaper, The Times. Our approach is diachronic: we study occurrences of different types of linguistic sexism in The Times' World news section that have occurred during the past five decades $(1965,1975,1985,1995$, \& 2005); more specifically, the following types of linguistic sexism and their non-sexist equivalents are investigated: male-as-norm (e.g., writer...he, writer...he or she), irrelevant reference to gender (e.g., chairman, police officer), irrelevant reference to domestic relationship (e.g., Mrs, Ms), and inappropriate forms of address (e.g., lady, boy). In addition, we investigate possible sexist discourses that may exist in The Times. The research method for the first four categories is quantitative, but for the fifth category it is qualitative.

Our hypothesis is that there has been a gradual decrease in the occurrences of linguistic sexism, but some forms, such as agent nouns with man suffix (e.g., chairman, spokesman), have been more resistant to change than others (e.g., generic he and man). We expected to find some forms of linguistic sexism, including sexist discourse, from all the decades under investigation. We also expected to discover an increase in the occurrences of non-androcentric generics (e.g., he or she), equal agent nouns (e.g., police officer), and the non-sexist social title Ms.

The results of this study show that masculine generics, especially generic he, were most open to change, they were almost non-existent by 2005. The most dramatic decline in this usage occurred between 1965 and 1975 . Agent nouns that reveal the gender of the person in question were most resistant to change. The use of non-androcentric generics has not, contrary to our hypothesis, increased significantly in The Times. However, the use of equal agent nouns has increased significantly since 1965. The results of the categories irrelevant reference to domestic relationship and inappropriate forms of address were indecisive. Each decade, except for the data from 1985, included some instances of sexist discourse.
\end{abstract}

Keywords: linguistic sexism, feminism, androcentric generics, agent nouns, social titles

\section{Introduction}

Language and gender is a diverse and rapidly developing research area. Especially since the rise of the feminist movement in the late 1960s and 1970s, linguists and other academics have begun to investigate the possible role of language in the subordination of women. Language and gender can be divided into two main research areas: sexism in language and its effects, and supposedly gender specific speech styles (Cameron, 1985, pp. 6-7; Litosseliti, 2006, p. 2).

The focus of this paper lies in sexism in language or linguistic sexism. Linguistic sexism includes, according to Wareing (2004, p. 77), discussion of the inherent sexism of the English language system as well as an exploration of different ways of using the English language in an unequal manner. Recently, in the $21^{\text {st }}$ century, the emphasis has shifted towards investigating gendered or sexist discourses instead of language as an abstract system (see, e.g., Litosseliti \& Sunderland, 2002; Litosseliti, 2006).

Feminists, such as Cameron (1998a, p. 9), believe that language is a powerful means of conveying, as well as reinforcing, the values and preoccupations of a given society. Hence, feminist oriented researchers have criticised the biased representation of men and women in languages and initiated reforms in order to eliminate this bias (Pauwels, 1998, p. x). The purpose of this paper is to investigate linguistic sexism in the British newspaper, The Times. Our approach is diachronic: we investigate the occurrences of different types of linguistic sexism in The Times' Overseas/World news section during the past five decades. The Times was chosen as a 
source of data mainly due to the following two reasons: it is one of the oldest and most well-known British newspapers, and also the only English newspaper that has been stored consistently onto microfilm in Finland since the end of the $19^{\text {th }}$ century.

We will look for the following types of linguistic sexism based on King's (1991) classification, and their non-sexist equivalents (when relevant): male-as-norm (e.g., writer...he, writer...he or she), irrelevant reference to gender (e.g., chairman, police officer), irrelevant reference to physical appearance or domestic relationship (e.g., Mrs, Ms), and inappropriate forms of address (e.g., girl, boy). In addition, we intend to investigate possible sexist discourses in The Times. A journalist may, for instance, use non-sexist words, but still convey sexist attitudes through other linguistics means. Sexist discourse cannot be revealed by a quantitative analysis of individual words or phrases. Hence, this part of our study will be qualitative.

The data is drawn from 1965, 1975, 1985, 1995, and 2005. The first year, 1965, represents the situation before the latter $20^{\text {th }}$ century feminist intervention in the English language. The Overseas/World news section was selected as a source of data mainly due to two reasons: it has remained more or less the same in format throughout the selected time period, and, according to the best of our knowledge, it has not been previously subjected to close scrutiny.

Our hypothesis is that there will be a gradual decrease in the occurrences of linguistic sexism, but some forms, such as occupational titles and other agent nouns with man suffix (e.g., chairman, spokesman), will be more resistant to change than others (e.g., generic he and man). We suspect that instances of irrelevant references to physical appearance and inappropriate forms of address are few and far apart, and are most likely to occur in the earlier part of the data. In relation to the qualitative part of this study, our hypothesis is that instances of sexist discourse can be discovered throughout the selected time period. Although we suspect that over time they have become less overt in nature, we still expect to find some forms of linguistic sexism from all the decades.

\section{Theoretical Background and Methods and Materials}

The data of this research consists of the Overseas (during 1965-1995) or World news (2005) section of The Times. We chose one week (six days) from each of the years 1965, 1975, 1985, 1995 and 2005. Therefore, our data covers a total of 30 days of World news. In this section, we will offer some comments on the selected section, and then present our investigation method and categorisation in greater detail.

\subsection{The Times}

The Times is one of the oldest and most well-known British newspapers. It was founded as early as 1785 (Westin, 2002, p. 7). Westin (2002, pp. 160-161), who has investigated the language of three British newspaper editorials: Daily Telegraph, Guardian and The Times, concludes that, out of these three quality newspapers, the language used by The Times is the most formal and less narrative. In other words, The Times has adopted a style that is known to be politically correct and precise. Therefore, we expect that our findings will be fairly subtle in nature. However, such a formal and conservative style may denote that The Times is more resistant to language change than more liberal newspapers.

Westin $(2002$, p. 7) explains that although The Times claims to be an independent newspaper, its political orientation is commonly considered to be right-wing. The political orientation of a newspaper is important because it has an influence on readership profiles. The social and financial status of the average readership is reflected in language choices. The largest proportion of the readership of The Times belongs to the upper middle-class and the second largest proportion to the middle-class (Westin, 2002, pp. 9-10). This further reinforces our assumption that we will not find any explicit instances of sexist language (e.g., insult words). Unfortunately, we were not able to find information about the gender readership of The Times.

We chose the section called the Overseas/World news as our source of data mainly because, in relation to content, it has remained more or less the same in format during the forty-year interval. The title has changed, but otherwise it is still a separate section that is easy to discover with the help of the contents page. Also, according to the best of our knowledge, it has not been investigated before. The World news includes different kinds of news reports from all over the world, although the emphasis is on politics (e.g., presidential elections and political nominations). Wars and natural disasters are also common subjects. We suspect that far fewer mentions of women than men occur in the articles, but hopefully women are discussed frequently enough to enable one to compare the type of language used towards the different sexes. We did not want to select articles according to the topic (unlike e.g., Granqvist, 1991), because we believe it would be an artificial means of gaining more instances of linguistic sexism. 
We managed to find an Online Style Guide of The Times from their internet pages (www.timesonline.co.uk). The Online Style Guide is an online version of The Times Style and Usage Guide (2003), which "aims to provide writers and sub-editors with a quick reference to contentious points of grammar and spelling and to guide them through specialised areas where confusions have arisen in the past." (Dixon, 2005). As mentioned, Penfield are not rules, as such, and much depends on the editor whether they are adhered to or not. Some of the matters that are relevant to this study are highlighted in the Online Style Guide of The Times, and will be discussed in the appropriate results sections.

\subsection{Methodology}

The objective of this research is to observe changes in newspaper language over a forty-year interval. 1965 was chosen as a starting point based on the assumption that reforms demanded by feminist academics and linguists would not have yet influenced the language usage of The Times. 2005 was the most recent source of data at the outset of this investigation. The years in between $(1975,1985$, \& 1995) are included in order to enable comparisons between different types of linguistic sexism and their resistance-or compliance - to change at ten-year intervals.

Our basic principle was to include all the articles published under the heading Overseas or World news during the first week of January of each of the selected years. However, The Times was not published on the first day of the year during the 1970s, 1980s and 1990s. Also, due to the tsunami disaster in South-East Asia there was no separate World news section during the first three days of 2005. All the articles discussed the tsunami disaster, and in order to avoid over-representation of one subject we excluded them from our data. Thus, the selected articles are from the following dates: 1-7.1.1965, 2-8.1.1975, 2-8.1.1985, 2-8.1.1995, and 4-10.1.2005 (in all, 30 days). The Times is not published on Sundays, which explains the missing days.

All the issues of The Times used in this study are available on microfilm at the National Library of Finland, Helsinki. In order to make comparisons between the different years we made copies of the selected articles, manually counted the number of words in those articles, and normalised the results per 1000 words. (Note 1) In addition, we tested our quantitative results for statistical significance. Altogether, the data for this research consists of 220658 words (see Appendix A).

Based on the theoretical background and previous studies conducted on linguistic sexism (especially Cooper, 1984; King, 1991; Granqvist, 1991) we formulated the following five categories and necessary sub-categories. In order to increase the reliability of this research, we also searched for non-sexist or non-androcentric (Cooper's term) words and expressions. All the examples are drawn from the data.

1) Male-as-norm: A) "androcentric generics", which are further divided into "generic he" and "generic man" B) "non-androcentric equivalents" for generic he and generic man: "he or she" and "men and women".

2) Irrelevant reference to gender: A) "man compounds" (e.g., chairman, policeman), which are further divided, according to referent, into "definitely male" and "not specified"; and "feminine affixes" (e.g., woman skier, actress) B) "equal equivalents" for man compounds and feminine affixes (e.g., police officer, actor (female)).

3) Irrelevant reference to domestic relationship: androcentric social titles Mrs, Miss, and the equal social title Ms.

4) Inappropriate forms of address: A) lady and girl as euphemisms of woman B) boy as a euphemism of man.

5) Sexist discourse.

The investigation method for the first four categories is quantitative, whereas the last category, sexist discourse, is qualitative in nature. Quotes, proper nouns, headlines, captions, and so forth are included in the results.

\subsubsection{Male-as-Norm}

The purpose of the first category is to investigate the tendency to represent men as the norm through the use of masculine generic constructions (i.e., use of generic he and man). The sub-category $1 \mathrm{~A}$ is formed by counting the occurrences of generic he, generic man, and their inflected forms. The criterion for inclusion is generic reference, even if the group referred to would consist most likely of men only. For instance, the position of a president was often referred to with generic he and man constructions. We realise that the use of masculine generics in relation to presidents would have been more acceptable in 1965 , for example, than in 2005 , when there actually were female presidents in different parts of the world. Hence, the criterion of inclusion is based on a modern definition of sexism, i.e., what is considered sexist today. However, the reader may be interested to know that already in 1965, a seemingly conservative country such as Pakistan had a female presidential candidate, Miss Jinnah. 
The following sentence is a fairly typical example of the generic use of the pronoun he:

(1) The town of Bonn proved, however, quite exemplary in this respect: not a single citizen had his driving licence removed. (2.1.1965, emphasis added)

The following example, on the other hand, represents a typical case of the generic man construction:

(2) In his remarks at the airport, Mr Callaghan likened the position of the Rhodesian rulers to that of men stranded in the middle of an ice-field. (2.1.1975, emphasis added)

Granted, the rulers that Mr Callaghan is referring to in example (2) were probably all male, but, according to our interpretation, in the metaphor the word men is used to denote people in general. Hence, it is counted as one occurrence of generic man. This group also includes other masculine words, such as brothers, which were used generically in the data.

Sometimes it was difficult to interpret whether man was used generically or not.

(3) He brings to the job a reputation as a man with a considerable intellect, who likes nothing better than to solve insoluble problems. (3.1.1985, emphasis added)

The referent in example (3) is definitely male, and it was not possible to decide whether the word man in the sentence referred to him as a man or as a human being. Therefore, these sorts of instances are not included in the results. As a rule of thumb, if we were not able to interpret from the context that the reference was made to a specific man or men, the occurrence was included in the results. This method should reveal the extent to which different masculine generics have been used, or are still used in the World news section of The Times.

"Non-androcentric equivalents", also known as true generics, are also divided into two further subcategories: "he or she" and "men and women". The sub-category "he or she" includes all different variations of he or she, as well as possible instances of singular they. The sub-category "men and women" includes words and expressions that are, according to our reading, used instead of the expressions in the sub-category "generic man" (e.g., men and women, brothers and sisters when used generically; person, people, and human being instead of generic man). The following sentence exemplifies the sub-category "men and women":

(4) The Cabinet approved a Bill today to make persons who have served prison sentences eligible for unemployment pay. (3.1.1975, emphasis added)

In example (4), we consider the word choice persons as an equal equivalent for the generic man construction. In the context, persons more clearly include former prisoners of both genders. The problem of investigating non-sexist language is that it is not as visible as sexist language. In order to avoid any misinterpretations, we have only included overt instances of non-sexist language in our results. The investigation of non-androcentric or equal equivalents for masculine generics should reveal whether the reforms suggested by feminist linguists are transferred into the actual language use of The Times.

\subsubsection{Irrelevant Reference to Gender}

The object of the second category is to investigate the extent to which occupational titles and other agent nouns marked with gender prefix or suffix have been used during the five decades. The second category is divided into A) "man compounds" and "feminine affixes" and B) "equal equivalents". The sub-category "man compounds" also includes verb forms derived from the root man (e.g., manned by guards).

The usage of man compounds is a complicated subject, and often a matter of opinion. As already mentioned, the stance of this study is that occupational and other agent nouns that reveal the gender of the person in question should be avoided. In this respect, our research differs, for instance, from Cooper (1984), who excluded definite references to men with man compounds from his results. Despite this, we acknowledge the difference between calling, for instance, a male police officer a policeman and referring to police officers, in general, or to female police officers, in particular, as policemen. Therefore, the category "man compounds" is further divided into those instances when the referent is definitely a man and to those instances when the gender of the referent is unclear or not specified, or the compound is used to refer to people in general (e.g., Frenchmen, congressmen).

We suspect that man compounds are still used, but they are used more often to refer to men than to women, or to groups that might include women. The next quote exemplifies the sub-category "not specified":

(5) Ten Xhosa tribesmen were killed in a series of faction fights in the [T]ranskei during the past week. (3.1.1975, emphasis added)

The context in example (5) does not reveal whether the tribesmen were actually all men. Hence, the word tribesmen in this sentence is placed in the above-mentioned sub-category "not specified". The sub-category 
"feminine affixes", on the other hand, consists of nouns that reveal that the person in question is a woman (e.g., housewife, actress).

The purpose of the "equal equivalents" category, 2B, is to document the frequency of feminist reforms, such as fire fighter and police officer, in The Times newspaper. We also included atypical wordings that are, in our opinion, applied with the purpose of avoiding the use of androcentric compounds. For instance, in example (6), the compound tribesmen is replaced by another, more equal, expression:

(6) But interviews here and in Luanda with health workers, religious leaders, military officials and international aid workers indicate that Dr Savimbi's guerrilla campaign has wrecked the economy of the Central Highlands and is causing enormous hardship for the people of Sawimbi's tribe. (7.1.1985, emphasis added)

The people of Sawimbi's tribe is an atypical, overtly inclusive expression. Thus, it is included in the results. Our hypothesis is that equal equivalents for man compounds and feminine affixes have increased in number since 1965.

\subsubsection{Irrelevant Reference to Domestic Relationship}

This third category concerns the usage of feminine social titles Mrs, Miss and Ms. We are interested in discovering how common the marriage-neutral coinage $M s$ is today compared to the titles Mrs and Miss that label woman according to her marital status. In distinction to the previous categories, we are not interested in the frequency of feminine social titles, as such, but in the possible changes that have occurred in the relative proportions of these titles. Hence, the results will be presented in percentages.

We discovered in earlier research that the same individual is often discussed multiple times and referred to with the same social title. For example, in 2005, the title $M s$ appeared 17 times, but actually referred to the same person, Ms Frey. This result would reveal more about the topicality of Ms Frey than changes in the frequency of the title $M s$. Therefore, we counted the combination of the same title (e.g., Ms) and name (e.g., Frey) only once per selected year. Hence, Ms Frey is counted as one occurrence of the new social title, Ms. Similarly, for example, Mrs Gandhi, was often discussed in 1985, but is counted as one occurrence of the social title Mrs. Consequently, the raw results of this section do not reveal the total amount of feminine social titles, but rather the amount of different women referred to with a social title (see Appendix G, Table G1).

The results do not reveal the total number of women mentioned in the World news section, either, because sometimes people are referred to by their professional titles (e.g., Dr. Margaret Mead) and sometimes by their whole name without a title. The title $M r$ is not included in the results. It would not be reasonable to compare the use of $\mathrm{Mr}$ against the use of feminine social titles because of the large disparity in the number of men and women represented in the World news section. Moreover, the title $\mathrm{Mr}$ has not been the subject of feminist language reform. Our hypothesis is that the proportions of androcentric social titles Mrs and Miss have diminished since 1965, benefiting the non-sexist social title $M s$.

We have not included instances of irrelevant reference to physical appearance in this section. These types of instances were too few and dispersed for a quantitative analysis, and will, instead, be presented in the category "sexist discourse".

\subsubsection{Inappropriate Forms of Address}

The fourth category is divided into A) lady and girl as euphemisms of woman, and B) boy as a euphemism of man. Researchers, such as Lakoff (1975) and Holmes (2004), are of the opinion that gentleman cannot be considered as a euphemism of man, because it does not carry a similar trivializing effect as the word lady. Hence, occurrences of gentleman are not taken into account in this research. We suspect that we will not discover many instances of inappropriate forms of address, but if they do occur, they are used in relation to adult women.

\subsubsection{Sexist Discourse}

Our data revealed instances of sexism that do not necessarily draw on sexist language items. We have added the qualitative category "sexist discourse" to this research in order to discover more subtle instances of sexist language. We have also included "irrelevant reference to physical appearance" in this last category, because quantitative methods proved to be insufficient in this respect. Our hypothesis is that instances of sexist discourse occur throughout the selected time period. However, we suspect that, over time, instances of sexist discourse will become more subtle in nature.

\section{Results and Discussion}

The main results of the empirical research are presented and discussed according to the methodology: male-as-norm, irrelevant reference to gender, irrelevant reference to domestic relationship, inappropriate forms 
of address, and sexist discourse. The raw results of the study, as well as other relevant information, are located in the Appendix.

\subsection{Male-as-Norm}

Figure 1 represents the total frequency of androcentric generics per 1000 words during each of the selected years. Normalization enables one to compare the results of the different years.



Figure 1. The total frequency of androcentric generics

As we can see, a dramatic decline occurred in the total usage of masculine generics between 1965 and 1975. In 1965, on average, 1,44 words in a thousand could be labelled as generics. However, by 1975 the number of generics had declined to only 0,43 occurrences per thousand words. A chi-square analysis found the raw data results to be statistically significant $(\mathrm{p}=0.00000262)$. The result supports our hypothesis that the feminist movement has definitely had an influence on the language use of The Times in regard to androcentric generics.

A slightly surprising discovery is that masculine generics seem to have been less frequent in 1985 than in 2005 . This result, however, is not supported by statistical evidence $(p=0.259)$, so may be a coincidence. Next, we expand these results by dividing the category "androcentric generics" into two subcategories: "generic $h e$ " and "generic man".

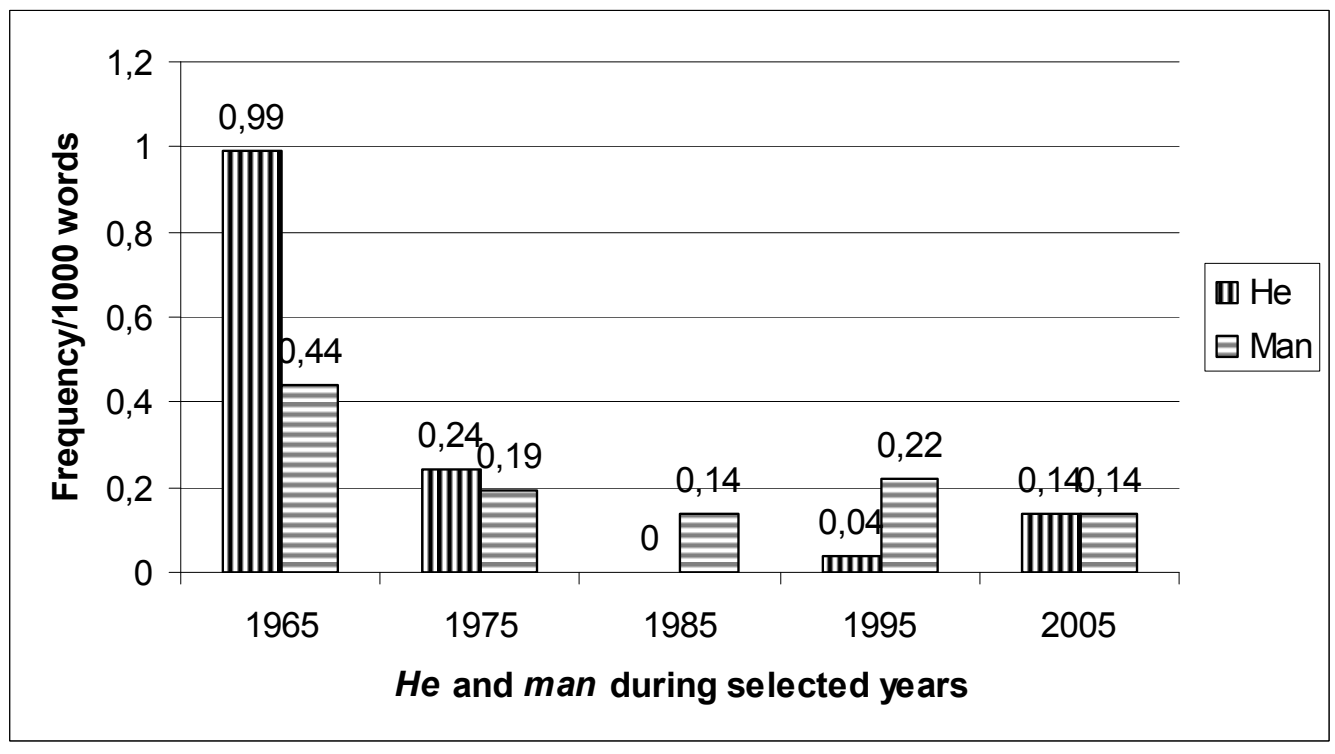

Figure 2. The frequency of generic he and man 
In 1965, 69,1\% of the androcentric generics belonged to the category "generic he" (see Appendix B, Table B3). This denotes that it was fairly common to refer to a person whose gender was unknown with masculine pronouns. For instance, the following extract is from the speech of the former President of the United States, Lyndon B. Johnson:

(7) It is difficult for any campaigning incumbent to avoid the accusation that he has used his office for political advantage, but President Ayub has made little or no attempt to separate his campaigning from his official self. (2.1.1965, emphases added)

Example (7) includes two occurrences of generic he. By 1975, the frequency for generic he had declined significantly to only 0,24 occurrences per 1000 words $(p=0.0000177)$.

The following extract from 1965 exemplifies the second sub-category, "generic man":

(8) Mr. Donald Campbell became the first man to break the world land and water speed records in the same year when he achieved an average speed 276.33 m.p.h. in Bluebird this afternoon. (1.1.1965, emphasis added)

A non-sexist version of example (8) would be “...the first person/human being...” The frequency of generic man had also declined over the ten-year interval (1965-1975), but not as radically as the frequency of generic he. Due to this, by 1975 , the proportion of generic he had diminished to $55,6 \%$, leaving $44,4 \%$ to generic man. In fact, the results for generic man do not differ significantly from the result for 1965 until $1985(p=0.010)$. Hence, it is safe to state that generic man is more resistant to change than generic he. In 1985, the data contained no instances of generic he.

Surprisingly, generic man seems to have been used more frequently in 1995 than in $1985(0,22 / 1000$ vs. $0,14 / 1000$ ). The chi-square analysis of the use of generic man in 1965 and in 1995 revealed that the results for 1995 do not differ significantly from the starting point of this investigation, $1965(\mathrm{p}=0.094)$. In 1995, only $16,7 \%$ of the total number of masculine generics belonged to the sub-category "generic he", and the rest to the sub-category "generic man". The next extract is an example of the use of generic man in 1995. The article at issue discusses new European commissioners and their respective posts.

(9) The most powerful man will not be Mr Santer, but Jim Cloos, a man hardly known except among a small group of insiders in Luxemburg or Brussels. (2.1.1995, emphasis added)

The first occurrence of man in example (9) is classified as an instance of generic man, because at least two of the new commissioners were women.

The results for 2005 are also surprising. In 2005, generic he was used significantly more than in 1985 ( $p=0.031)$, and slightly more than in $1995(\mathrm{p}=0.296)$. According to the raw results, there were, in total, five instances of generic he in 2005, but closer investigation of the data revealed that all those instances were from the same interview with an Iraqi police officer.

(10) Asked what he would tell anyone considering signing up as policemen, he thinks hard. "If he was a friend, and I really liked him, I'd slam him in the face. If I advised him to join it would mean I really hated him." (6.1.2005, emphases added)

It is not possible to say whether the police officer's words are translated or not, i.e., whether the reporter of the article used the generic he construction or whether the officer did. However, we decided to include all quotations in the results, and, therefore, we consider it appropriate to include this quotation, as well. We are aware that there probably are not any female police officers in Iraq, which makes this sentence more acceptable than, for instance, referring to British police officers with the pronoun he. Drawing the line between less severe and more severe instances of generic he would have been, however, extremely difficult, so we decided against it.

The frequency of generic man has diminished slightly since 1995 (0,22/1000 vs. $0,14 / 1000)$, but the result is not statistically significant $(p=0.5335)$. In 2005 , equal number of occurrences were included in the sub-categories generic he and generic man. The following extract exemplifies the language use of The Times in 2005 in relation to generic man:

(11) In a barricaded cell within the Muqata, Khaled Shawish, a founder of Fatah's armed al-Aqsa Martyr's Brigades, believes that his men will support Fatah's candidate. (8.1.2005, emphasis added)

Example (11) is included in the results, because the context does not reveal that Khaled Shavish was talking about some specific male supporters of his. It is likely that the dominant Palestinian Fatah faction has female supporters, as well. 


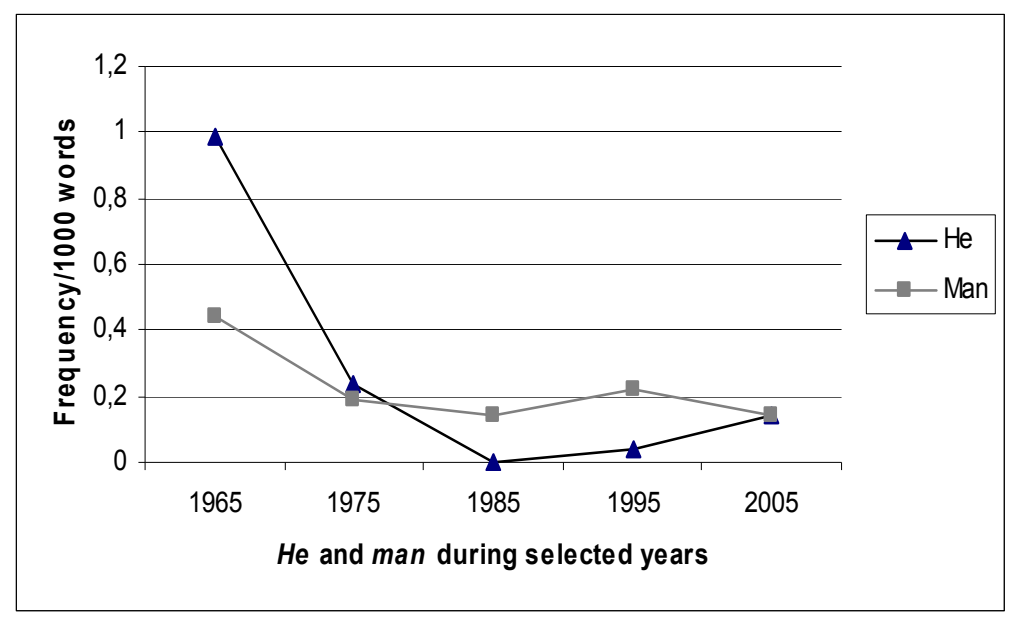

Figure 3. The development of generic he and man over five decades

Figure 3 displays the results of Figure 2 in a different format. It enables the reader to see the development of masculine generics throughout the selected time period more clearly. Since 1975, the frequency of generic man, in particular, has remained surprisingly level. One possible explanation for the dramatic decline in the frequency of both masculine generics in a relatively short period of time (1965-1975) is that the subject was topical then. This would also explain the lower frequencies of 1985 compared to 1995 and 2005. Continuation of this research would reveal whether the use of masculine generics will, in fact, become more acceptable in the future. Next, we present the results for category $1 \mathrm{~B}$, "non-androcentric equivalents" for generic he and man.

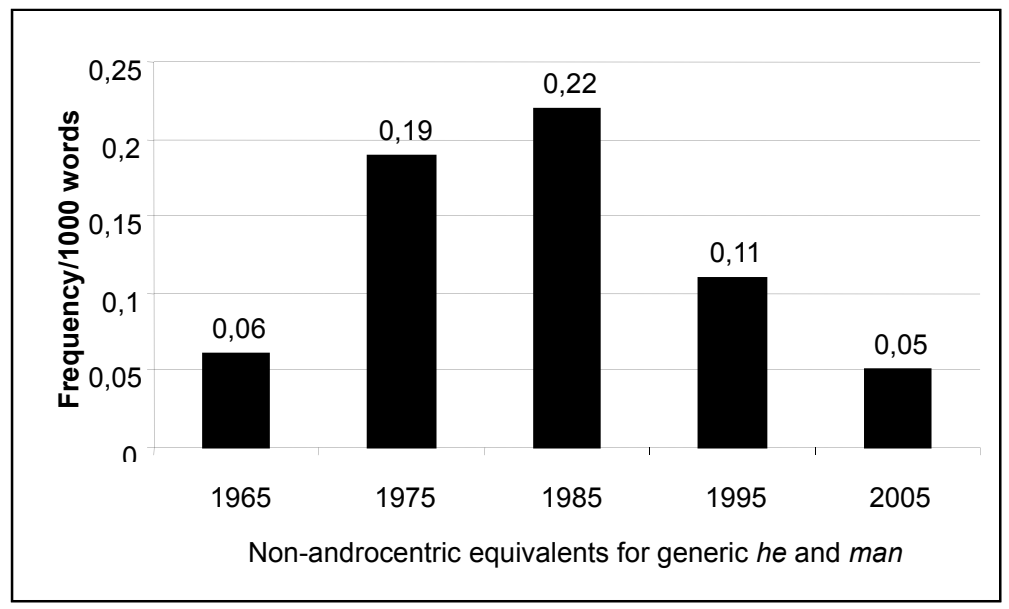

Figure 4. The total frequency of non-androcentric generics

In all, we discovered only 29 non-androcentric or equal generics amongst the corpus of 220638 words (on average 0,13 words per 1000). Therefore, the results are not particularly fruitful and will be discussed fairly briefly. Figure 4 represents the total frequency of non-androcentric generics during each year. Surprisingly, the highest frequency of these generics was in $1985(0,22 / 1000)$. Thereafter, the frequencies seem to decline. None of the results for non-androcentic generics are, however, statistically significant. One may draw a conclusion that, contrary to our hypothesis, the use of equal generics has not increased significantly in The Times in the course of four decades. Figure 5 represents the distribution of the two groups of non-androcentric generics over the selected time period. 


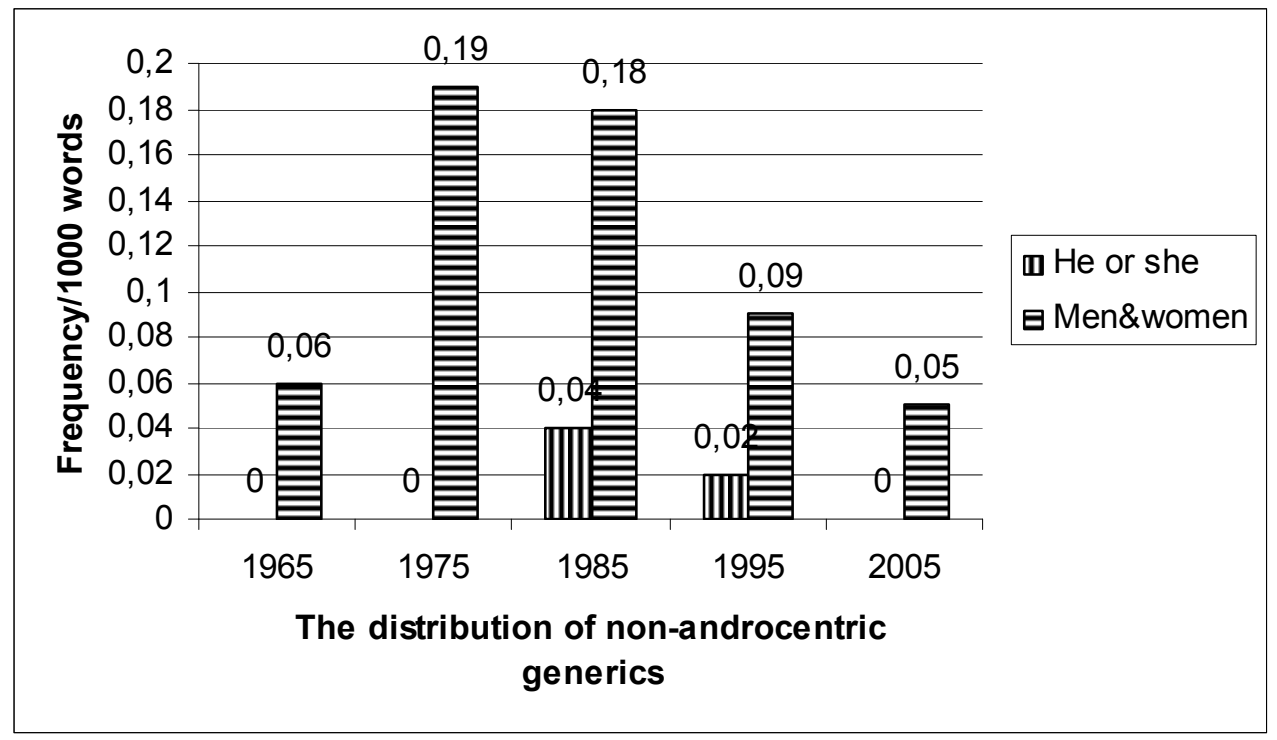

Figure 5. The distribution of non-androcentric equivalents for masculine generics

\begin{abstract}
Altogether, the data included only three occurrences that can be placed in the sub-category "he or she", which is far less than we expected (see Appendix C, Table C1). The first two occurrences of he or she are from 1985, and the third one from 1995. It appears that this particular reform rarely enters the language used by the journalists of The Times. In addition, the data contained no instances of the singular they construction, which is another suggested method to avoid the use of generic $h e$.

The frequency of the other sub-category, "men and women", is higher than the frequency of the category "he or she" during each year. The frequencies are highest in 1975 and 1985, which would support our theory that the subject of linguistic sexism was more topical during the 1970s and 1980s. The results are not, however, supported by statistical evidence. The following extracts from 1975 and 1985 exemplify the category "men and women". Example (12) is from a speech of the former French President, M Giscard d'Estaing, and example (13) is from a caption.
\end{abstract}

(12) "All those who hold authority must use it, not to assert their own importance, but to serve the public interest; not for the satisfaction of their own preferences or ideas, but for the satisfaction of the men and women who make up our nation." (2.1.1975, emphasis added)

(13) Around the Horn: David Hempleman-Adams, a 27-year-old explorer from Bristol, showing the flag after becoming the first person to paddle a canoe round Cape Horn, at the southern tip of South America. (2.1.1985, emphasis added)

Example (12) overtly includes women into the reference group. Another interesting matter in the extract is that it uses pluralisation; possibly in order to avoid the generic he construction. Pluralisation and other sorts of changes in sentence structures are not included in the results, because, unfortunately, it is not possible to predict whether a certain sentence structure was used in order to avoid generics, or, for instance, for stylistic purposes.

Figures 4 and 5 suggest that overtly non-sexist expressions were used more in 1975 and 1985 than in 1995 and 2005. This does not, however, automatically denote that the current language use of The Times would be more sexist than the language used in the 1970s and 1980s, given the low frequency of androcentric generics, as well. However, according to the combined results, it appears that 1985 was the least sexist year in relation to generics: it contained the lowest frequency of androcentric generics and the highest frequency of non-androcentric equivalents for androcentric generics. Next, we will present the results of the second category, "irrelevant reference to gender".

\title{
3.2 Irrelevant Reference to Gender
}

This category includes all occupational titles and other agent nouns that reveal the gender of the person in question, as well as their inflected forms (e.g., chairmanship). First, we present the results for the sub-category "man compounds". 


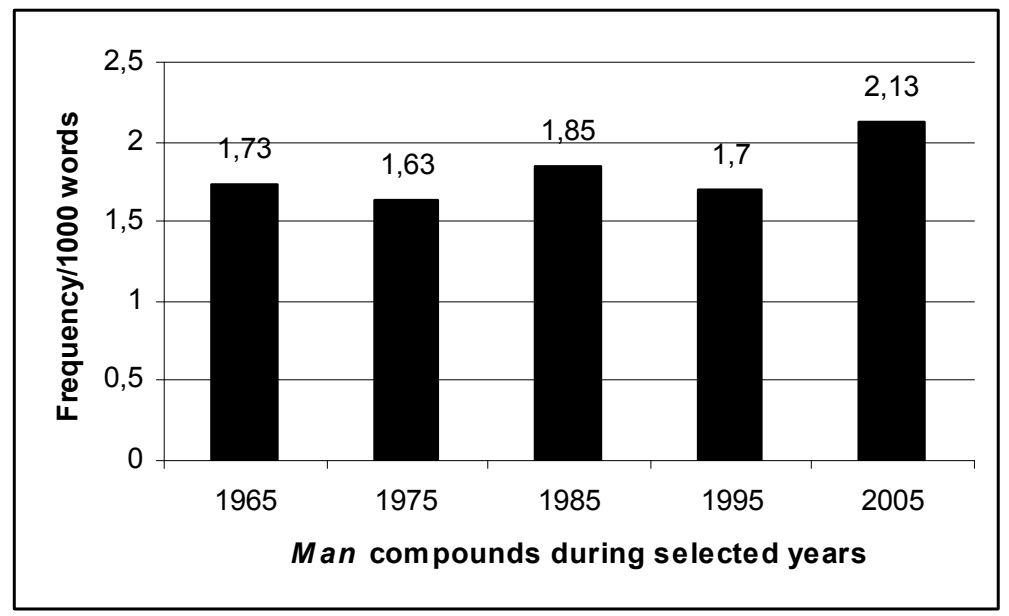

Figure 6. Total frequency of man compounds

Figure 6 represents the frequency of all man compounds during the selected time interval. Unexpectedly, the highest frequency of these nouns was in 2005 ( 2,13 per 1000 words). The frequencies before the $21^{\text {st }}$ century have remained relatively level. The result for 2005 does not, however, differ significantly from the results for the other years. Hence, it can be stated, contrary to our hypothesis, that the feminist movement has not had an influence on the total usage of man compounds. A larger corpus might reveal whether the current Times, in fact, uses more of these compounds than The Times of the 1960s. The next figure, Figure 7, represents the distribution of man compounds according to the referent, i.e., whether the referent is definitely male or not.

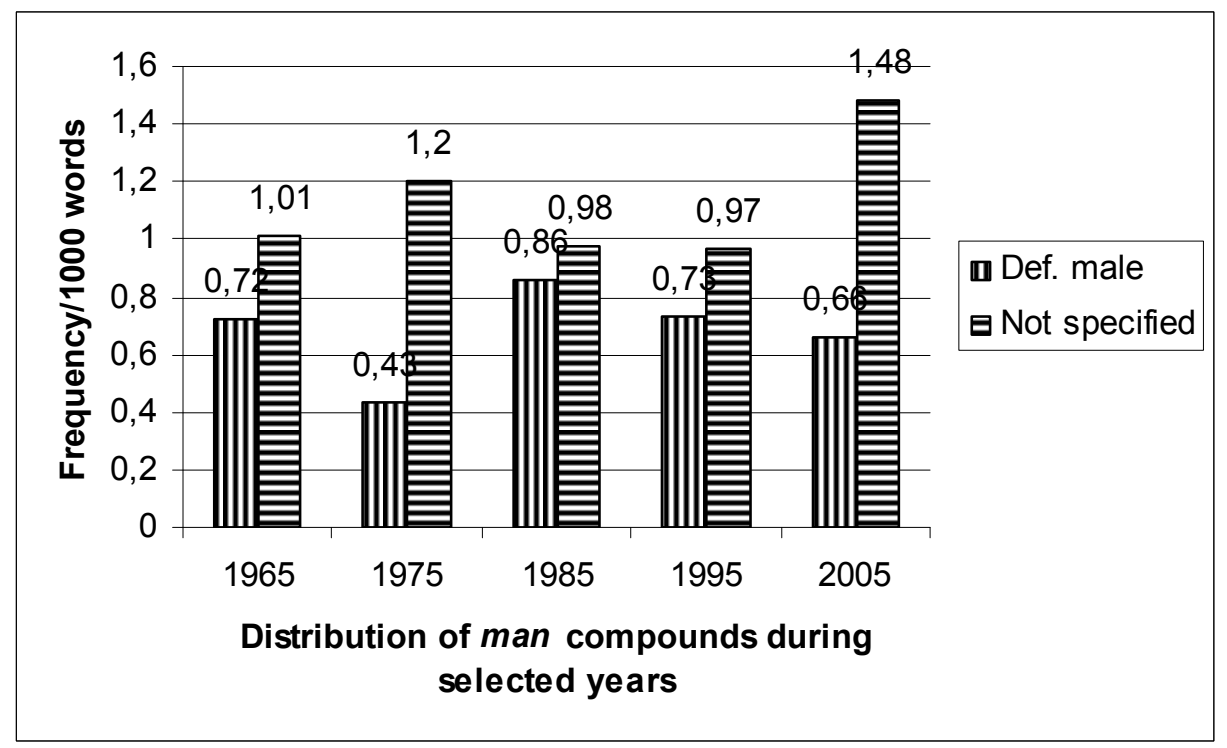

Figure 7. Distribution of man compounds according to the referent

Surprisingly, the results visible in Figure 7 disprove our hypothesis that man compounds were presently used mainly to refer to groups or individuals that are definitely male. The frequency of the sub-category "not specified" was, in fact, slightly higher in 2005 than in $1965(1,48 / 1000$ vs. 1,01/1000). Although the difference between 1965 and 2005 is not significant $(\mathrm{p}=0.070)$, it is interesting that in $196558,5 \%$ of the occurrences of man compounds referred to an unspecified individual or group of people, whereas in 2005 the percentage was 69,2 (see Appendix D, Table D3).

The most typical man compounds over the years were policeman, chairman, and spokesman (both singular and plural). It is worth highlighting that although the majority of people in these occupations were, at least in the earlier decades, male, women have held those positions, as well. For instance, in 1965, China nominated at least 
one female vice-chairperson, Mrs Li Teh-chuan, to the new Chinese Government (6.1.1965). The following extracts from 1965 and 2005 exemplify the first sub-category, "definitely male".

(14) The threats of the Klan and the burning of crosses brought about the cancellation of a talk on racial integration to have been given in Bogalusa, Louisiana, by Mr. Brooks Hays, a former Arkansas congressman . (7.1.1965, emphasis added)

(15) The United Democratic Front is split between supporters of Mr Mutharika and the man he succeeded last May, Bakili Muluzi, who remains chairman of the party. (6.1.2005, emphasis added)

The following extracts exemplify the sub-category "not specified".

(16) Mrs Patricia Riley Hitt, the vice-chairman of the foundation executive board [...] (2.1.1975, emphasis added)

(17) Less certain will be the outcome of House and Senate votes on limiting how long congressmen may serve. (2.1.1995, emphasis added)

Example (16) is one of the few instances of the usage of masculine generic noun in reference to a woman. This is not to say that women were usually referred to with neutral or non-androcentric nouns, but that references to women at all were few and far apart. Example (17) is from an article that discusses the new Congress of the United States. It is situated into the category "not specified", because the compound congressmen was used in reference to members of congress, in general. In this instance, the group that the word congressmen is referring to definitely includes women, as well.

(18) Twenty-two National Guardsmen die with their driver in suicide bomb. (5.1.2005, emphasis added)

The classification of example (18) was slightly more complex. It is situated into the above-mentioned category since it was impossible to interpret from the context whether the dead soldiers in Iraq were, in fact, all men. The phrase National Guardsmen was used fairly often in 2005 and created some confusion. The phrase was sometimes used in reference to the National Guard of the United States, which also includes female soldiers, and sometimes in reference to the Iraqi National Guard, which most probably includes only men. In example (18) the dead soldiers were, apparently, members of the Iraqi National Guard, hence male, but, lacking any definite information, we situated it into the category "not specified".

Another common compound in 2005, and, to lesser extent, in 1995, was gunman (both singular and plural). It was used as a universal term for fighters, criminals, and so forth. We placed most of the plural forms, gunmen, into the category "not specified", because the context often did not reveal whether the group included women or not. The word itself carries a negative connotation and cannot be described as particularly sexist towards women. Compare gunmen, for instance, to congressmen: one might aspire to be included in the latter group but not necessarily in the former. However, for the sake of clarity, we decided to include all man compounds to the results without the classification of the words by definition. In 2005, there were ten occurrences of gunmen out of the total of 54 occurrences in the category "not specified". Hence, the high frequency of the above-mentioned category in 2005 does not necessarily denote that the language use of The Times would have been more sexist in 2005 than in the earlier years.

The next figure, Figure 8, presents the results of the sub-category "feminine affixes". As we can see, the frequencies of feminine affixes are relatively low throughout the time period under study. This probably results from the case that far less women than men were discussed in the World news section. 


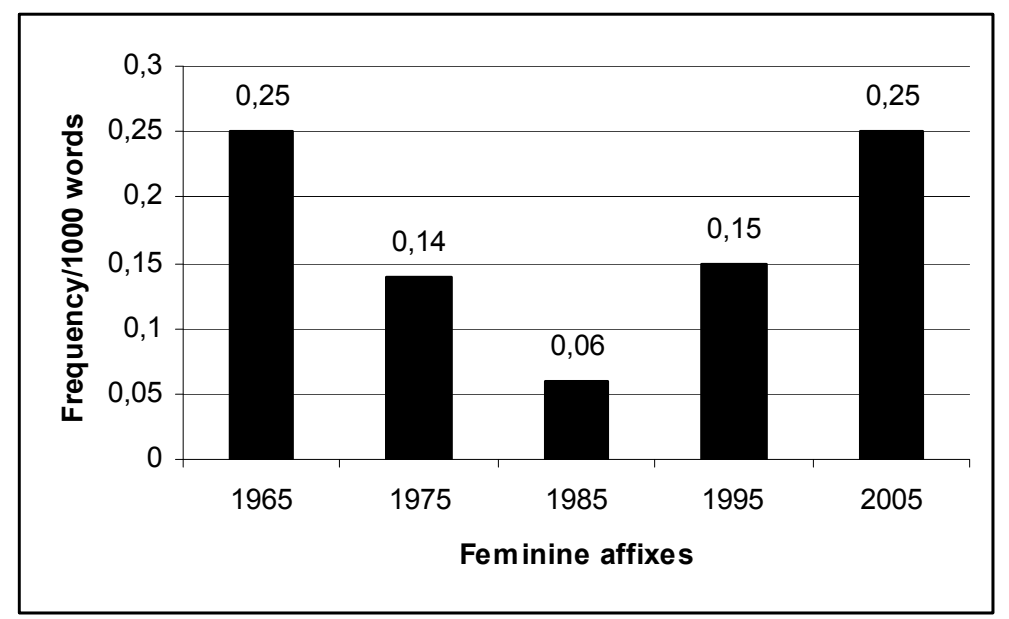

Figure 8. Agent nouns with feminine affixes

Again, contrary to our hypothesis, the results for this research do not attest to the fact that the contemporary Times would use less feminine affixes than The Times of the 1960s. The frequency of feminine affixes did decline significantly if one compares 1965 to $1985(\mathrm{p}=0.030)$. However, after reaching its lowest point in 1985, the frequency of feminist affixes began to ascend. The difference between 1985 and 2005 is statistically significant $(\mathrm{p}=0.046)$.

One factor that one must take into account while interpreting Figure 8 is the improvement in the overall position of women since the 1960s. We have not counted the exact number of women mentioned in The Times, but, according to our observation, the number has steadily increased since 1965. The increase in feminine affixes since 1985 may, in fact, indicate that women were mentioned more often by their profession during the latter years of this research rather than that feminine affixes, as such, were used more often. This is a limitation of a quantitative research, but, despite this, it is safe to state that, contrary to the intention of feminist language reformers, The Times does not avoid the use of agent nouns that reveal the gender of the person in question.

The following extracts exemplify the sub-category "feminine affixes":

(19) It is already statistically proved that the average Italian housewife is inclined to pay the highest price for any product. (1.1.1965, emphasis added)

(20) Refugees from Ang Snuol Tonw, 16 miles south-west of here, said insurgent forces, including women fighters, occupied the main road linking the capital with the port of Kompong Som. (2.1.1975, emphasis added)

(21) The Pentagon refused to be drawn on the issue yesterday. "We don't discuss specific future operations or specific tactics," a spokeswoman said. (10.1.2005, emphasis added)

Examples (19) and (20) are fairly typical examples of the language usage of the earlier decades of this research. Traditional gender roles were reflected, or promoted, through language choices. In example (19) the author of the article gives the impression that the only people who buy groceries are married women who stay at home to take care of their family. One might presume that, even in Italy of the 1960s, this was not the case. In example (20), the journalist foregrounds female fighters as an exception. Unexpectedly, the compound spokeswoman was still used in 2005. This matter will be discussed more thoroughly in context of the next figure that presents the results of the sub-category "equal equivalents". 


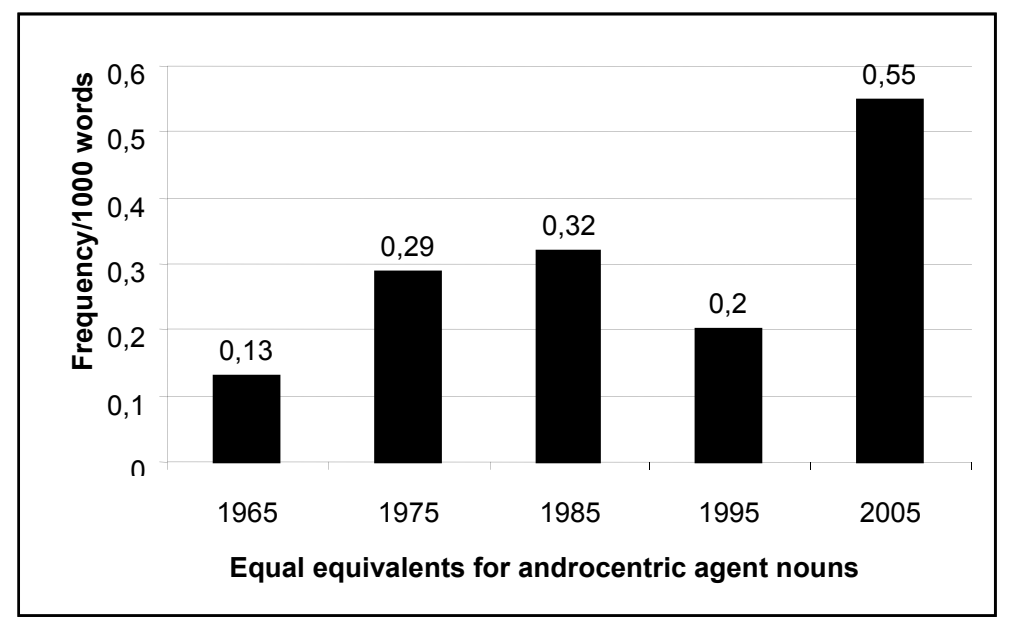

Figure 9. Equal agent nouns

The category "equal equivalents" includes phrases such as in the chair, professional and business people, and the coinage police officer. We also included the cases in which the word police is used as a person rather than an institution in the results (e.g., ten customs police). The number of equal equivalents for man compounds and feminine affixes has remained relatively low throughout the time frame of this research. However, except for a slight hiccup in 1995, the frequencies of equal agent nouns seem to be slowly ascending. The results for 2005 differ significantly from the results for $1965(\mathrm{p}=0.001)$. Hence, our hypothesis in this respect has proven to be correct.

The most common coinage throughout the range of the data was police officer. The first instance of the word already occurred in 1965, but the usage has increased since. It has not, however, replaced the word policeman, which was still in general usage in 2005. Surprisingly, not a single compound with the suffix person was found. The data for 1965 also included instances of in the chair and police as a person. It appears that these are old usages that have always been used, to some extent, in English. The results for 2005 include compounds such as security guards (instead of security men) and business executive (instead of businessman). The following example is from 2005 :

(22) The actor Catherine Deneuve has been questioned as a witness in an investigation into a French television station. (6.1.2005, emphasis added)

In comparison to the previous years, it is quite exceptional to refer to a woman as an actor instead of actress. This was not, however, a general rule of The Times, because the data from 2005 also included two instances of the word actress. Perhaps Catherine Deneuve prefers to be called an actor or the journalist him- or herself has made the decision. Usually, though, actor was used in reference to men or the profession in general.

The most surprising discovery in relation to occupational titles and other agent nouns is the fact that man compounds were still regularly used in 2005 when the people in question were definitely or most likely all men. As becomes apparent from the difficulties we encountered while classifying masculine nouns into different sub-categories, the existence of different terms for men and women often creates confusion in the readers' mind and may lead to misuse.

Different words differ in their contemporary usage. The compound policewoman did not appear in the data. However, a female spokesperson was commonly called a spokeswoman (three instances in 1995 and two in 2005). Unfortunately, the data included no references to female chairpersons after the year 1975, but the compound chairman was used in reference to men and to chairpersons or vice-chairpersons in general.

According to the Online Style Guide (2005), spokeswoman and spokesman are, indeed, acceptable language, although they should be avoided when possible. The guide offers official as an alternative to spokesman or spokeswoman. The use of spokesperson is forbidden. We have not included official in the category "equal equivalents", though, because it may refer to any official and not only to spokespersons. Unfortunately, in most cases, the guide offers no explanation as to why it forbids certain expressions and recommends others. Clearly the stance of The Times is that compounds including the word person are not acceptable English. 
For the other words in relation to this section, the Online Style Guide (2005) comments on the use of chairman, policemen, fire fighters, and feminine designations. The guide states that chairman "is still the common usage referring to men and women, except in quotes, but chairwoman is acceptable" (Online Style Guide, 2005). Chair and chairperson should be avoided. The author of the guide also advises writers to be careful with the word policemen, because "certain senior officers, men and women, regularly chide us for using policemen when we mean police officers" (Online Style Guide, 2005). According to our results, not all writers follow this advice.

The guide takes a stronger stance in regard to the compound firemen and advises writers to avoid it altogether because "a substantial number in the Fire Service are now women" (Online Style Guide, 2005). According to the Online Style Guide (2005), feminine designations (i.e., feminine affixes), such as authoress, should be avoided. The exception to this rule is actress, which is acceptable due to its common usage (ibid.). This might explain example (22): the writer is given the freedom to choose the usage she or he prefers.

According to the results of this study, and the additional information offered by The Times Online Style Guide (2005), one can conclude that the compound chairman is particularly resistant to change. Also, the singular is generally more acceptable than the plural. Of the feminine affixes, actress may become replaced by actor over time. Fire fighter seems to be the most successful coinage suggested by feminist language reformers, although police officer is also a part of common language usage today.

\subsection{Irrelevant Reference to Domestic Relationship}

The third category is concerned with the progression of feminine social titles Mrs, Miss, and the coinage Ms. As a reminder, we are not interested in the total frequency of feminine social titles, but in the possible changes that have occurred in the relative proportions of these titles. In order to enhance the reliability of this research, the combination of the same name and title is counted only once per year.

The raw results for this category are situated in the Appendix (Table G1). Unfortunately, due to the low number of women discussed in the World news section, in general, no clear conclusions can be made about the progression of feminine social titles. None of the results are supported by statistical evidence. However, the total number of different women referred to with feminine social titles appear to have declined during the forty-year interval, although the result was not supported by statistical evidence $(p=0.155)$. According to our observation, this results from the new habit of referring to people. Before the 1990s, it was exceptional to refer to a person with his or her whole name. Whole names without an additional title were only used in sports reporting, or when the person in question had passed away. In 1995 and 2005, however, all people in news reporting were first introduced by their first and last name without any title. Social and professional titles were used in subsequent references. For instance, in 2005, the Palestinian President was first referred to as Mahmoud Abbas, and after that as Mr Abbas.

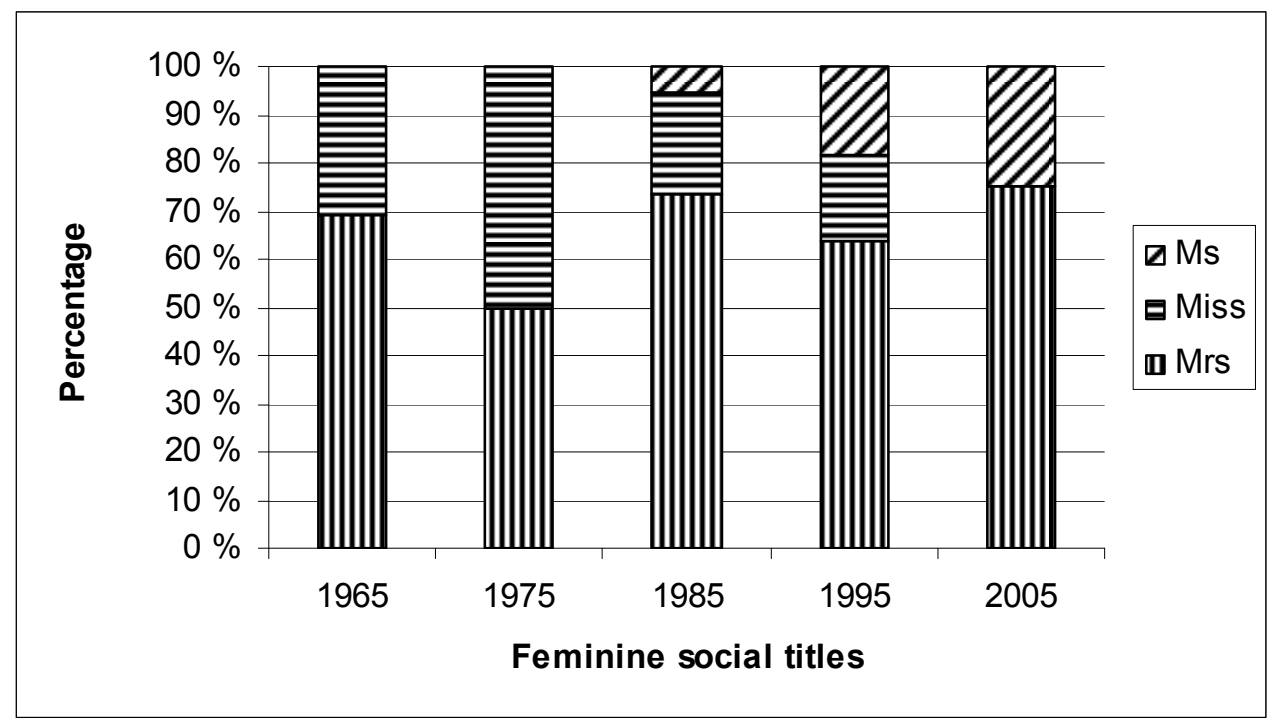

Figure 10. Distribution of Mrs, Miss, and Ms during selected years 
Figure 10 presents the results for Mrs, Miss, and $M s$ in percentages. Predictably, there were no instances of the coinage Ms in 1965. 69,2\% of the total 13 different women were referred to as Mrs, and the rest as Miss. In 1975, exactly half of the women were given the status of Mrs, and the other half were referred to as Miss. The coinage Ms made its debut in 1985 in the following sentence:

(23) Mr John Zaccaro, husband of Ms Geraldine Ferraro, the former democratic vice-presidential contender, is said to be considering a plea of guilty involving a falsified sales contract for five apartment buildings in Queen's, New York City. (8.1.1985, emphasis added)

In example (23) the marriage-neutral title $M s$ has been used instead of Mrs, despite the fact that Ms Geraldine Ferraro was clearly married.

Surprisingly few women were referred to as $M s$ in the latter years of this investigation: two individuals in 1995, and one in 2005. This may partly be explained by the decline in the overall usage of social titles. Despite this, it is clear that the original objective of the coinage $M s$ has not been achieved. In $1995,81,8 \%$ of the women were referred to with androcentric social titles. The same figure for 2005 is $75 \%$. Women are still usually classified according to their marital status, although, according to the results for 2005, the title Miss for unmarried women seems to have lost its popularity. In fact, it seems that Ms has replaced Miss, but the results are inadequate for making any definite conclusions. Also, unfortunately, the results do not reveal whether the title $M s$ is nowadays most commonly used in relation to married women, unmarried women, or equally in relation to both. According to The Times Online Style Guide (2005), " $M s$ is nowadays fully acceptable when a woman (married or unmarried) wants to be called thus, or when it is not known for certain if she is Mrs or Miss" (emphases added).

On the one hand, the language use of The Times, in relation to social titles, has become more equal. One method of eliminating the unequal usage of feminine and masculine social titles would be, nonetheless, the avoidance of all social titles. This appears to be the current trend, although it might be more related to clarity rather than to the avoidance of linguistic sexism. On the other hand, the reader might be interested to know that, according to preliminary research by us, even in 2005 , the combined results for different feminine social titles formed only $14,4 \%$ of the total number of all social titles. The masculine social title, $M r$, dominated the results by $85,6 \%$. Hence, there still is an alarmingly vast disparity between the number of women and men mentioned in The Times' World news section, which cannot be repaired by eliminating all social titles, or by further promoting the use of Ms.

\subsection{Inappropriate Forms of Address}

The object of the fourth category was to investigate changes in the usage of A) lady and girl as euphemisms of woman, and B) boy as a euphemism of man. These types of euphemisms were, however, surprisingly few, so they will only be discussed briefly. Altogether the data included only 9 references to adult women as ladies or girls, and 7 references to adult men as boys (see Appendix H, Table H1). Compounds girlfriend and boyfriend were included in the results. The occurrences were fairly evenly distributed between the different years, although the data from 1965 included, unexpectedly, no instances of either sub-category.

The following extract exemplifies the usage of girl as a euphemism of woman:

(24) Strange stories are circulating in West Germany about the true nature of the traditional English afternoon tea. My source is a Yorkshireman married to a West German girl. (4.1.1975, emphasis added)

In example (24) the asymmetry between the words Yorkshireman and West German girl is evident. Presumably, both of them were adults when they got married. These types of examples were few and far apart, though. The two occurrences from 2005 were ex-girlfriend and former girlfriend, which were used in reference to adult women.

The small quantity of occurrences in the first sub-category "lady and girl" may result from the lack of women discussed in the data, at all, or from the fact that these euphemisms were simply not common in the language use of The Times during the period of this research. However, we suspect the former, because The Times' Online Style Guide (2005) advises journalists not to use lady or girl as a synonym of woman. Also, journalists are advised to use girlfriend only in reference to young people. To gain a special reference in the Style Guide, the subject must have been topical at some point. A more extensive database would be needed in order to reveal the accurateness of these speculations.

A slightly surprising discovery was the fact that white adult men were, as well, sometimes referred to with the trivializing word boy. In the data, boy was sometimes used in reference to newly appointed politicians. The following example is from a headline of an article concerning new members of the American Congress. 
(25) New boys of radical revolution told what to read. (6.1.1995, emphasis added)

Beside from the fact that some of the new "boys" were probably "girls", the usage of boy, in this context, emphasizes the politicians' status as beginners in the Congress. Hence, it functions in a similar way to the euphemistic use of girl. Unfortunately, no other conclusions can be made based on the current data, despite the fact that both men and women were sometimes, but not frequently, referred to with trivializing terms in the past and contemporary Times.

\subsection{Sexist Discourse}

Finally, we will compare the language used during each year of this research with the help of some other types of linguistic sexism discovered from the data. As already explained, sexist discourse does not necessarily draw on sexist language items, as such. Nonetheless, some of the example extracts presented in this section include familiar types of linguistic sexism presented in the earlier sections of this chapter, as well.

As might have been expected, the language used in 1965 contained many instances of sexist discourse that do not fit into any narrow, predefined categories. The following extract is from an article that concerns the state of French farming.

(26) A principal factor in plans for agriculture, therefore, is the need to keep some young people on the land. Young people become farmers by choice rather than automatically following in their fathers' footsteps, and they want better conditions than have existed until now. They want to have holidays and to go on specialized courses, and they want better lives for their wives and families. (6.1.1965, emphases added)

We have used italics in order to highlight the problem areas of example (26). The phrase young people in the extract is an example of what Pauwels (1998, p. 50) calls false generics: the beginning of the extract seems to refer to all young people, but as it turns out, young people actually only refer to young men. For most parts, example (31) follows the Penfield of non-sexist language usage, but, still, the overall impression is sexist. According to our knowledge, at least in Finland, women have always contributed to the farm work as much as men have. The data from 1965 included many similar types of sexist discourse that sideline women's contributions to society and portray them in relationship to men, only.

The data from 1975 did not differ greatly from the data of 1965 regarding sexist discourse. Women, as a rule, were marked as an exception, and false generics were fairly common.

(27) Martial law authorities have released 1,017 people, including 141 women, detained after riots last month over the burial of U Thant, former United Nations Secretary-General. (4.1.1975, emphasis added)

(28) Asked whether a Muslim settled in Britain would be allowed more than one wife, Mr Lyon said that in Britain British law was applicable and therefore only one wife would be given an entry permit. (6.1.1975, emphases added)

Wordings similar to examples (27) and (28) were discovered both from the years 1965 and 1975. In the extracts people and Muslim are examples of false generics. The main problem of the language used in both 1965 and 1975 was that it often, intentionally or unintentionally, portrayed the world from a masculine point of view.

These types of references did not occur in the data from 1985. The general impression of the language used in 1985 is that it was surprisingly equal and inclusive. We did not discover any obvious instances of sexist discourse. We suspect that the subject of sexism in language was most widely discussed in Britain in the late 1970 and the early 1980s, and this influenced the language used by The Times.

Surprisingly, the data from 1995 appears to be less equal in relation to sexist discourse than the data from 1985. It did not include as many, or as obvious, instances of sexist discourse as 1965 and 1975, but it was not as equal as the data from 1985, either. The following extract offers an example of the type of sexist discourse discovered from 1995.

(29) The Renaissance Weekend was started 13 years ago by a local businessman and his wife with the aim of bringing together modern "renaissance" men and women. (2.1.1995, emphasis added)

The biggest problem with example (29) is not the use of the masculine compound, but the unequal representation of the sexes: the woman is simply "his wife" although they obviously started the Renaissance Weekend together. In comparison, in a similar incidence in 1985 the phrase a local couple was used. The following extract is a slightly different example of sexist discourse: 
(30) Standing more than six feet tall, Major Rose Kabuye, the new prefect of Kigali, commands respect. [...] Charming and intelligent as Major Kabuye is, as a representative of a popularly detested military Government she will be hard-pressed to woo donors. (3.1.1995, emphases added)

The extract does not contain sexist language, as such, and is probably intended as a positive description of a woman of stature. However, it differs greatly from the descriptions of male members of the military. The extract includes some elements of irrelevant reference to physical appearance, but, most of all, it seems patronizing and supports old stereotypes: charming AND intelligent women are exceptional, especially in the military.

We offer two examples from 2005, which are actually quite similar to examples (29) and (30).

(31) A judge dismissed a claim for almost $£ 46$ million against the FBI by Stephen Rakes, a former liquor storeowner, and his ex-wife, who said that they were extortion victims (6.1.2005, emphasis added)

(32) Murderer's lover rushes into print with "kiss and kill" tale. Ms Frey's book [...] features dozens of photographs of the curvy massage therapist, including a "glamour" shot taken when she was 18. Other black-and-white pictures show a short-haired Ms Frey wearing a see-through negligee. (5.1.2005, emphasis added)

In example (31), we find it peculiar that, although the couple clearly filed the claim together, only the man is described by his name and profession. In example (32), an unnecessary emphasis is placed on the woman's appearance. Surprisingly, instances similar to examples (31) and (32) were not discovered from the earlier years of this research. Our initial hypothesis in regard to sexist discourse has proven to be fairly correct: except for 1985, all the years included instances of sexist discourse. In addition, the instances of sexist language have become more subtle in nature, if one compares examples (26)-(28) to examples (29)-(31). Example (32), however, is surprisingly sexist considering the year of its publication.

\section{Conclusion}

Our initial thesis was that, due to feminist intervention in the English language, linguistic sexism in the World news section of The Times has gradually decreased since 1965 . We also suspected that some forms, such as occupational titles and other agent nouns with man suffix, would be more resistant to change than others (e.g., masculine generics). According to the results of this study, however, the latter part of our hypothesis has proven to be more correct than the former.

Of the different forms of linguistic sexism discussed in this study, masculine generics, particularly generic he, were least resistant to change. Masculine and feminine occupational titles and other agent nouns, on the other hand, were most resistant to change. More precisely, the frequency of both man compounds and feminine affixes remained surprisingly level throughout the forty-year interval. The division of man compounds, according to referent, into "definitely male" and "not specified" also disproved the hypothesis that man compounds were presently used mainly to refer to groups or individuals that are definitely male. Hence, the feminist language reform has not had a direct influence on the frequencies of agent nouns that reveal the gender of the person in question. This result supports Ehrlich and King's (1994, p. 63) conclusion that the classification of people according to gender is relevant to the speech community.

Contrary to our hypothesis, the frequency of non-androcentric generics has not increased significantly in The Times since 1965. Different versions of he or she were particularly unpopular amongst the data. It is peculiar that generic he declined so dramatically without a compensating rise in the use of he or she. This implies that some other methods, such as pluralisation, are used in order to avoid the use of generic he. The frequency of equal equivalents for androcentric agent nouns, on the contrary, has increased significantly since the feminist intervention in the English language, although the number of these equivalents has remained surprisingly low.

Contrary to Cooper (1984), we did find a definite decline in the use of masculine generics in this particular British publication. Despite this, the results that he obtained from the American corpus are, in some respects, consistent with the results for our study. According to Cooper's (1984) research, generic man was least resistant to change, which differs from our results, but he, as well, concluded that man compounds were most resistant to change. Cooper (1984) did not discover any definite increase in the use of non-androcentric generics, either. Unlike Cooper, however, we did find a clear increase in the use of non-androcentric agent nouns. This might result from the longer time span of our research. There are, at least, a few more women in contemporary news reporting, and some of them prefer to be referred to by non-masculine terms.

Disappointingly, the results for the category "irrelevant reference to domestic relationship" were inadequate for making any definite conclusions other than the fact that the non-sexist social title, $M s$, is nowadays sometimes used in reference to women, apparently regardless of their marital status. Although our study does not offer any 
clear results for the contemporary usage of feminine social titles, it is congruent with previous research (e.g., Ehrlich \& King, 1994): $M s$ has not become the female equivalent of $M r$.

The fourth category, "inappropriate forms of address", included, likewise, too few occurrences for the purposes of a quantitative research. A more extensive database would be needed in order to study the use of lady and girl as euphemisms of woman, and boy as a euphemism of man. In addition, a different section of The Times, for instance the sports section, would probably have yielded more instances of these euphemisms.

The results for the final category, "sexist discourse", proved to be slightly more interesting. The data included occurrences of false generics similar to Cameron's (1996) findings. According to our study, false generics were fairly common in the 1960s and 1970s, as the articles were often written from a male point of view. However, it was surprising that irrelevant descriptions of women's appearance were few, and were only discovered from the latter sections of this study's database (1995 and 2005). Despite some instances of sexist discourse, our data did not include anything comparable to Clark's (1992) and Cameron's (1998) findings. British tabloids would probably be more suitable for an investigation of sexist discourse, and inappropriate forms of address, alike.

Of the five years selected for this research, 1985 appeared to be surprisingly equal: it contained the lowest frequency of androcentric generics and feminine affixes, the highest frequency of non-androcentric generics, and no instances of either inappropriate forms of address or sexist discourse. The quantitative results for 1985 did not, however, differ significantly from the results for 1995 and 2005 and may be due to a coincidence. The data from 2005 , respectively, contained the highest frequency of equal equivalents to masculine and feminine agent nouns, as well as the highest proportion of the non-sexist social title, $M s$.

Despite the progress that has occurred in relation to many aspects of linguistic sexism since the 1960s, the most alarming matter, in our opinion, is the continuing under-representation of women in news reporting. This may, in part, result from the chosen section of The Times. It would be interesting to investigate linguistic sexism in the domestic news section of The Times, and compare the results to this research. Another possibility for future research would be an investigation of the impact of feminist language reform upon American newspapers. Future researchers of linguistic sexism should, however, take into consideration the relative invisibility of women, at least in foreign news reporting, and choose their data accordingly. A much more extensive database would be needed in order to properly investigate social titles, euphemisms, inappropriate forms of address, and sexist discourse.

\section{Acknowledgments}

This paper is based upon Tarutuulia Laine's original, unpublished MA research, University of Eastern Finland.

\section{References}

Cameron, D. (1985). Feminism and Linguistic Theory. London: Macmillan.

Cameron, D. (1996). Sukupuoli ja kieli (2nd ed., Finnish translation of Feminism and Linguistic Theory (1992)). Tampere: Vastapaino.

Cameron, D. (Ed.). (1998). The Feminist Critique of Language (2nd ed.). London: Routledge.

Cameron, D. (1998a). Introduction: Why is language a feminist issue? In D. Cameron (Ed.), The Feminist Critique of Language (2nd ed., pp. 1-28). London: Routledge.

Clark, K. (1992). The linguistics to blame: Representations of women in the Sun's reporting of crimes of sexual violence. In D. Cameron (Ed.), The Feminist Critique of Language (2nd ed., pp. 183-197). London: Routledge.

Cooper, R. (1984). The avoidance of androcentric generics. International Journal of the Sociology of Language, 50, 5-20. http://dx.doi.org/10.1515/ijsl.1984.50.5

Ehrlich, S., \& King, S. (1994). Feminist meanings and the (de)politicization of the lexicon. Language in Society, 23, 59-76. http://dx.doi.org/10.1017/S004740450001767X

Granqvist, T. (1991). Linguistic sexism and its change in newspapers: A comparative analysis of editorials and other texts of the Guardian and The Times (Master's thesis, Tampere, Microfilm).

Holmes, J. (2004). Power, lady, and linguistic politeness in Language and Women's Place. In M. Bucholtz (Ed.) Language and Woman's Place: Text and Commentaries. New York: Oxford University Press.

King, R. (1991). Talking Gender: A Guide to Non-sexist Communication. Toronto: Copp Clark Pitman Ltd.

Lakoff, R. (1975). Language and Woman's Place. New York: Harper Colophon. 
Litosseliti, L. (2006). Gender and Language. London: Hodder Education.

Litosseliti, L., \& Sunderland, J. (2002). Gender identity and discourse analysis: Theoretical and empirical considerations. In L. Litosseliti, \& J. Sunderland (Eds.), Gender Identity and Discourse Analysis (pp. 1-39). Amsterdam: John Benjamin Publishing Co. http://dx.doi.org/10.1075/dapsac.2

Mills, S. (Ed.). (1995). Language and Gender: Interdisciplinary Perspectives. London: Longman.

Online Style Guide. (2005). The online version of The Times Style and Usage Guide. Retrieved from $\mathrm{http}: / / \mathrm{www} . t i m e s o n l i n e . c o . u k / t o l / t o o l s \_a n d \_s e r v i c e s /$ specials/style_guide/

Pauwels, A. (1998). Women changing language. London: Longman.

Penfield, J. (Ed.). (1987). Women and Language in Transition. Albany: State University of New York Press.

Spender, D. (1985). Man Made Language (2nd ed.). London: Routledge \& Kegan Paul.

The Concise Oxford Dictionary. (2001). Oxford: Oxford University Press.

The Oxford English Dictionary. (1989). Oxford: The Oxford University Press.

Wareing, S. (2004). Language and Gender. In L. Thomas, \& S. Wareing (Eds.), Language, Society and Power (2nd ed.). London: Routledge.

Westin, I. (2002). Language Change in English Newspaper Editorials. New York: Rodopi B.V.

\section{Note}

Note 1. At present, the National Library offers a possibility to transfer data directly from microfilm to a computer, but that option was not available at the outset of this investigation in the academic year 2005-2006.

\section{Appendix A}

Words per year

\begin{tabular}{|r|r|}
\hline 1965 & 47,365 \\
\hline 1975 & 41,631 \\
\hline 1985 & 49,768 \\
\hline 1995 & 45,322 \\
\hline 2005 & 36,572 \\
\hline Total & 220,658 \\
\hline
\end{tabular}

\section{Appendix B}

\section{Androcentric generics}

Table B1. Raw quantities

\begin{tabular}{|r|r|r|r|}
\hline & $H e$ & Man & Total \\
\hline 1965 & 47 & 21 & 68 \\
\hline 1975 & 10 & 8 & 18 \\
\hline 1985 & 0 & 7 & 7 \\
\hline 1995 & 2 & 10 & 12 \\
\hline 2005 & 5 & 5 & 10 \\
\hline
\end{tabular}


Table B2. Normalised per 1000 words

\begin{tabular}{|r|r|r|r|}
\hline & He & Man & Total \\
\hline 1965 & 0.99 & 0.44 & 1.44 \\
\hline 1975 & 0.24 & 0.19 & 0.43 \\
\hline 1985 & 0 & 0.14 & 0.14 \\
\hline 1995 & 0.04 & 0.22 & 0.27 \\
\hline 2005 & 0.14 & 0.14 & 0.27 \\
\hline
\end{tabular}

Table B3. Percentage

\begin{tabular}{|r|r|r|}
\hline & $\mathrm{He}$ & Man \\
\hline 1965 & 69.12 & 30.88 \\
\hline 1975 & 55.56 & 44.44 \\
\hline 1985 & 0 & 100 \\
\hline 1995 & 16.67 & 83.33 \\
\hline 2005 & 50 & 50 \\
\hline
\end{tabular}

\section{Appendix C}

\section{Non-androcentric generics}

Table C1. Raw quantities

\begin{tabular}{|r|r|r|r|}
\hline & He or she & Men \& women & Total \\
\hline 1965 & 0 & 3 & 3 \\
\hline 1975 & 0 & 8 & 8 \\
\hline 1985 & 2 & 9 & 11 \\
\hline 1995 & 1 & 4 & 5 \\
\hline 2005 & 0 & 2 & 2 \\
\hline
\end{tabular}

Table C2. Normalised

\begin{tabular}{|r|r|r|r|}
\hline & He or she & Men \& women & Total \\
\hline 1965 & 0 & 0.06 & 0.06 \\
\hline 1975 & 0 & 0.19 & 0.19 \\
\hline 1985 & 0.04 & 0.18 & 0.22 \\
\hline 1995 & 0.02 & 0.09 & 0.11 \\
\hline 2005 & 0 & 0.05 & 0.05 \\
\hline
\end{tabular}




\section{Appendix D}

\section{Man compounds}

Table D1. Raw quantities

\begin{tabular}{|r|r|r|r|}
\hline & Def. male & Not specified & Total \\
\hline 1965 & 34 & 48 & 82 \\
\hline 1975 & 18 & 50 & 68 \\
\hline 1985 & 43 & 49 & 92 \\
\hline 1995 & 33 & 44 & 77 \\
\hline 2005 & 24 & 54 & 78 \\
\hline
\end{tabular}

Table D2. Normalised

\begin{tabular}{|r|r|r|r|}
\hline & Def. male & Not specified & Total \\
\hline 1965 & 0.72 & 1.01 & 1.73 \\
\hline 1975 & 0.43 & 1.2 & 1.63 \\
\hline 1985 & 0.86 & 0.98 & 1.85 \\
\hline 1995 & 0.73 & 0.97 & 1.7 \\
\hline 2005 & 0.66 & 1.48 & 2.13 \\
\hline
\end{tabular}

Table D3. Percentage

\begin{tabular}{|r|r|r|}
\hline & Def. male & Not specified \\
\hline 1965 & 41.46 & 58.54 \\
\hline 1975 & 26.47 & 73.53 \\
\hline 1985 & 46.74 & 53.26 \\
\hline 1995 & 42.86 & 57.14 \\
\hline 2005 & 30.77 & 69.23 \\
\hline
\end{tabular}

\section{Appendix E}

\section{Feminine affixes}

\begin{tabular}{|r|r|r|}
\hline & Raw & Normalised \\
\hline 1965 & 12 & 0.25 \\
\hline 1975 & 6 & 0.14 \\
\hline 1985 & 3 & 0.06 \\
\hline 1995 & 7 & 0.15 \\
\hline 2005 & 9 & 0.25 \\
\hline
\end{tabular}




\section{Appendix F}

\section{Equal equivalents}

\begin{tabular}{|r|r|r|}
\hline & Raw & Normalised \\
\hline 1965 & 6 & 0.13 \\
\hline 1975 & 12 & 0.29 \\
\hline 1985 & 16 & 0.32 \\
\hline 1995 & 9 & 0.2 \\
\hline 2005 & 20 & 0.55 \\
\hline
\end{tabular}

\section{Appendix G}

\section{Feminine social titles}

Table G1. Raw quantities

\begin{tabular}{|r|r|r|r|r|}
\hline & Mrs & Miss & Ms & Total \\
\hline 1965 & 9 & 4 & 0 & 13 \\
\hline 1975 & 5 & 5 & 0 & 10 \\
\hline 1985 & 14 & 4 & 1 & 19 \\
\hline 1995 & 7 & 2 & 2 & 11 \\
\hline 2005 & 3 & 0 & 1 & 4 \\
\hline
\end{tabular}

Table G2. Percentage

\begin{tabular}{|r|r|r|r|}
\hline & Mrs & Miss & Ms \\
\hline 1965 & 69.23 & 30.77 & 0 \\
\hline 1975 & 50 & 50 & 0 \\
\hline 1985 & 73.68 & 21.05 & 5.26 \\
\hline 1995 & 63.64 & 18.18 & 18.18 \\
\hline 2005 & 75 & 0 & 25 \\
\hline
\end{tabular}

\section{Appendix H}

\section{Inappropriate forms of address}

Table H1. Raw quantities

\begin{tabular}{|r|r|r|r|}
\hline & Lady \& girl & Boy & Total \\
\hline 1965 & 0 & 0 & 0 \\
\hline 1975 & 3 & 1 & 4 \\
\hline 1985 & 2 & 1 & 3 \\
\hline 1995 & 2 & 4 & 6 \\
\hline 2005 & 2 & 1 & 3 \\
\hline
\end{tabular}

\section{Copyrights}

Copyright for this article is retained by the author(s), with first publication rights granted to the journal.

This is an open-access article distributed under the terms and conditions of the Creative Commons Attribution license (http://creativecommons.org/licenses/by/3.0/). 